\title{
A RELAÇÃO ENTRE O CRESCIMENTO DA MECANIZAÇÃO E A QUEDA NAS QUEIMADAS DOS CANAVIAIS NOS ESTADOS DE GOIÁS E MATO GROSSO DO SUL
}

\author{
Roberto Bernardo ${ }^{1}$ \\ Wagner Luiz Lourenzani ${ }^{2}$ \\ Cristiane Hengler Corrêa Bernardo ${ }^{3}$
}

\begin{abstract}
RESUMO
Analisar a relação entre o aumento da mecanização para a colheita da cana e a redução na prática das queimadas é o objetivo geral deste artigo que tem como espaço de análise os estados do Mato Grosso do Sul e de Goiás. Especificamente, pretende-se aferir a área de plantio da cana-de-açúcar em ambos os estados; determinar o uso da mecanização para a colheita, na região de análise, correlacionando as áreas com a utilização de máquinas às áreas com colheita manual precedidas de queimada da palha e por fim, verificar a qual legislação os dois estados estão sujeitos e o que as mesmas preveem com relação às queimadas. Esses objetivos pretenderam responder à questão que se apresenta para este artigo: a mecanização tem sido um instrumento eficiente para a redução da prática da queimada da cana na preparação para a colheita? Para tanto, este artigo utilizou como método de análise a pesquisa bibliográfica de dados secundários, assim como legislação e dados primários obtidos junto ao IBGE e ao CTC. Os resultados indicam que a redução das áreas com queima da palha da cana, no locus de análise, apresenta uma redução significativa e que esta não se restringe à exigência legal, mas sim a fatores econômicos atribuídos à eficiência da mecanização que reduz os custos de produção se comparada à colheita manual precedida da queimada do canavial.
\end{abstract}

PALAVRAS-ChAVE: Queimadas. Cana-de-açúcar. Colheitamecanizada

\section{Mechanization adoption and sugarcane pre-harverst burning decrease in Goiás and Mato Grosso do Sul}

\begin{abstract}
The objective of this paper is to analyze the relationship between harvest mechanization and sugarcane pre- harvesting burning in Goias and Mato Grosso do Sul. More specifically, the paper intends to quantify sugarcane area, mechanization system, establish a correlation between mechanized and pre-harvest burning systems in the area and verify both states legislation regarding the issue. The proposed objectives aim at answering the following question: is mechanization an

\footnotetext{
${ }^{1}$ Engenheiro Mecânico formado pela UNESP, mestrando em Agronegócio e Desenvolvimento Unesp - Câmpus de Tupã. rbernardo@tupa.unesp.br

${ }^{2}$ Doutor em Engenharia de Produção pela UFSCAR; mestrado em Ciência e Tecnologia de Alimentos pela Universidade Federal de Viçosae graduado em engenharia de alimentos pela mesma universidade. Professor Assistente Doutor do Câmpus da Unesp em Tupã. wagner@tupa.unesp.br ${ }^{3}$ Doutora em Educação pela UFMS, Mestre em Comunicação pela UNESP e graduada em jornalismo pela PUCCAMP. Professora Assistente Doutora do Câmpus da Unesp em Tupã. cristiane@tupa.unesp.br
} 
efficient strategy for sugarcane pre-harvesting burning practice? In order to answer this question, a secondary data bibliographical research was performed. Legislation and data from IBGE and CTC were used. The results indicate that there has been a significant reduction in pre-harvesting burning in the studied areas. Besides following legislation, the reduction is due to economic motivation from mechanization efficiency and cost reduction.

\title{
La relación entre el crecimiento de la mecanización y la caída de la quema de plantaciones de caña de azúcar en los estados de Goiás y Mato Grosso do Sul
}

\begin{abstract}
Resumen
Analizar la relación entre la ampliación de la mecanización de la cosecha de la caña de azúcar y la reducción de las quemas es el objetivo general de este artículo que tiene como espacio de análisis los estados de Mato Grosso do Sul y Goiás. Específicamente, se pretende hacer una averiguación en el área de plantío de la caña de azúcar en los dos estados. Determinar la utilización de la mecanización para la cosecha en la región de análisis y correlacionar las áreas que utilizan maquinaria en áreas con conseja manual precedida de la quema. Finalmente, verificar en cual legislación los dos estados están sujetos y lo que las mismas pronostican con relación a la quema. Esos objetivos pretenden responder la cuestión principal para este artículo: ¿la mecanización es un instrumento eficiente para la reducción de la quema de la caña de azúcar en la preparación para la cosecha? Este artículo utilizó como método de análisis la investigación bibliográfica de datos secundarios, la legislación y datos primarios obtenidos en el Instituto Brasileño de Geografía y Estadística/IBGE y al Centro de Tecnología de la Caña de Azúcar. Los resultados indican que la reducción de las áreas con quema de la paja, en el locus de análisis, presenta una reducción significativa que no se restringe a la exigencia legal, pero a los factores económicos atribuidos a la eficiencia de la mecanización que reduce los costos de producción en comparación a cosecha manual precedida de la quema de la caña de azúcar.
\end{abstract}

PALABRAS CLAVES: Quema de la caña. Caña de azúcar. Cosecha mecanizada

\section{Introdução}

A expansão da cana-de-açúcar, principalmente após o advento dos motores flexfuel, trouxe para o Brasil uma ampla alternativa energética, contudo, junto também vieram muitos outros de ordem ambiental, social e econômica.

A substituição de culturas como o café, a laranja, o amendoim, assim como das atividades pecuárias, pelas vastas áreas ocupadas pela cana-de-açúcar, de maneira intensiva, apontam para um problema crescente no abastecimento de alimentos no mundo. 
Os problemas encaminham-se ainda em direção a questões que vão desde a eliminação de grande parte dos empregos no campo, favorecendo um novo êxodo rural e o surgimento de problemas urbanos graves, como: a violência, a falta de moradia, o crescimento desordenado das cidades, até problemas ambientais, tais como: a degradação do solo, qualidade do ar devido às queimadas, entre tantas outras discussões que se baseiam na má utilização dos recursos naturais (GONÇALVES; FERRAZ; SZMRECSÁNYI, 2008).

Só para se ter uma ideia da representatividade da cultura canavieira para a economia brasileira, em 2012, de toda a produção mundial de cana-de-açúcar, o Brasil foi responsável por 39\% desse total, seguido pela Índia com $19,6 \%$ e pela China com 6,7\% (AGRIANUAL, 2014).

O Brasil não é apenas o maior produtor como também ocupa o lugar de maior exportador de açúcar do mundo. A safra 2014/2015 apresentará uma produção de cerca de 659,1 milhões de toneladas de cana-de-açúcar, volume muito próximo ao verificado na safra 2013/2014. Esse resultado se deve a influência dos efeitos climáticos negativos devido à forte seca ocorrida na região Centro-Sul (CONAB, 2014).

Neves (2014)afirma que o crescimento da produção de cana-de-açúcar, nos últimos 20 anos, mais do que duplicou no Brasil. Esse crescimento, no entanto, não se deu de forma equitativa no país. Algumas regiões, mais recentemente, passaram a ter papel de destaque para a cultura em análise. Segundo Demattê (2014), o Centro-Oeste assumiu o papel de segundo maior produtor do país, e a região onde a cultura mais tem avançado em área plantada.

Destacam-se, nessa dinâmica, os Estados do Mato Grosso do Sul e Goiás. Os referidos estados obtiveram, no período entre 1990 e 2013, crescimento da produção de cana-de-açúcar, na ordem, respectivamente de 1011,1\% e 1006,0\%, sendo que no Brasil o crescimento foi de $292,4 \%$, no período (IBGE, 2015).

Embora os benefícios econômicos trazidos com a expansão do setor sucroalcooleiro sejam significativos, um dos grandes problemas apresentados pela expansão dos canaviais no Brasil como um todo e, em alguns estados em especial, como no Mato Grosso do Sul e em Goiás, áreas da última expansão agrícola, são os impactos ambientais (GONÇALVES; FERRAZ; SZMRECSÁNYI, 2008). 
Pode-se dizer que a expansão canavieira trouxe em seu bojo, um dos maiores desafios a serem enfrentados pelas instâncias governamentais federais, estaduais e municipais - o controle dos impactos ambientais causados, principalmente, pelas queimadas.

Ainda é bastante comum em algumas regiões a prática de queima da palha da cana com o objetivo de facilitar a colheita. Como resultado dessa prática, além da poluição do ar causada pela fumaça e pela fuligem e, que podem ocasionar até problemas respiratórios na população do entorno dos canaviais, ainda se têm as emissões de gases que colaboram para o efeito estufa, principalmente, o gás carbônico (CO2), além do monóxido de carbono (CO), do óxido nitroso (N2O), do metano $(\mathrm{CH} 4)$ e da formação do ozônio (O3) (ANTUNES; AZANIA e AZANIA, A., 2015).

Os problemas de ordem ambiental, referentes à poluição, são evidentes, no entanto, estes não ficam restritos apenas a esta questão. A queimada da cana, na visão de Antunes; Azania e Azania, A. (2015), acarretam impactos sob várias perspectivas. Os autores apresentam tais impactos perante quatro visões distintas. A visão agronômica vê, entre as principais desvantagens da queimada da palha da cana, o fato de que as altas temperaturas e a profundidade que estas atingem, agravam a fertilidade do solo. Tal gravidade é evidenciada nas consequências que acarretam, como, por exemplo, a eliminação de predadores naturais de algumas pragas, favorecendo o uso de agrotóxicos em maior quantidade; o crescimento de ervas daninhas após a queima e, que tem como efeito, uma maior utilização de herbicidas; ocasiona ainda uma maior erosão do solo e, por fim, um grande desequilíbrio ecológico.

Do ponto de vista industrial, Antunes; Azania e Azania, A. (2015) afirmam que a queima da palha dificulta a conservação e a purificação dos caldos, o que potencializa o teor de sólidos solúveis (Brix) e de fibras. Tais fatores favorecem a infestação de microrganismos acelerando o processo de deterioração do produto. A visão econômica e operacional indica que, apesar da colheita tornar-se mais fácil e barata, os prejuízos, nos casos em que ocorre o atraso do corte, podem ocasionar problemas com o tratamento de água da lavagem. Por fim, na perspectiva energética, as queimadas têm ocasionado a perda de aproximadamente $30 \%$ da 
matéria orgânica que poderia ser aproveitada para a geração de energia, por meio da biomassa.

Apesar de todos os grandes problemas decorrentes da prática da queimada, pode-se encontrar um alento, pelo menos para os problemas ambientais. Dois fatores específicos vêm colaborando para a redução da queima da palha. O primeiro é a legislação, que vem impondo limites para tal prática, estabelecendo inclusive um cronograma que cria um planejamento para a extinção da prática de queimada a curto e médio prazo. O segundo fator é o que este artigo pretende discutir - a mecanização como instrumento para a redução das queimadas.

O plantio e a colheita mecanizados, de acordo com o CTC (2012), vêm se expandindo de forma muito rápida na região Centro-Sul do país. No que se refere à colheita mecanizada, que é o aspecto que interessa para esta pesquisa, uma vez que é nesta etapa que se substitui a queimada da cana, os dados apontam que na região citada, em 2012, três quartos da colheita foi feita por meio da mecanização e com cana crua, o que significa que inexistiu, nessa área bastante significativa, a queima da palha da cana-de-açúcar.

Em uma média histórica de dez anos, levantados pelo CTC (2012), o crescimento da colheita mecanizada na região Centro-Sul passou de uma taxa de 34\% em 2003 para 85\% em 2012. De acordo com o Centro, o crescimento está ligado à adesão dos produtores em se adequarem ao protocolo ambiental, que prevê a eliminação total das queimadas até 2021, mas que entre 2014 e 2017 já há a perspectiva da prática estar extinta.

Entretanto, o protocolo ambiental é restrito ao Governo do Estado de São Paulo; questiona-se então, qual fator tem ocasionado essa redução da queimada nos Estados do Mato Grosso do Sul e de Goiás.

O Mato Grosso do Sul utilizava a colheita mecanizada em 95\% das áreas em 2012, ocupando o primeiro lugar em índice de colheita por máquina. Goiás, por sua vez, passou de $70 \%$ de colheita mecanizada em 2011 para aproximadamente 90\% em 2012, representando, na região Centro-Sul, o estado que mais aumentou a mecanização em um ano (CTC, 2012).

Nesse contexto, este artigo se dispõe a relacionar a implementação da mecanização na região de nova expansão agrícola, especificamente nos estados do 
Mato Grosso do Sul e de Goiás, com a redução da prática de queimada. Logicamente, a análise do fator mecanização terá que ser ponderado pela existência ou não da exigência legal que proíbe as queimadas.

Para tanto, parte-se da seguinte questão: a mecanização tem sido um instrumento significativo para a redução da prática da queimada da cana na preparação para a colheita?

\section{Objetivos}

Analisar a relação entre o aumento da mecanização para a colheita da cana e a redução na prática das queimadas é o objetivo geral deste artigo.

Como objetivos específicos esta pesquisa pretende: aferir a área de plantio em ambos os estados; determinar o uso de mecanização para a colheita na área de análise; verificar se essa área utiliza a prática da queimada e, por fim, verificar a qual legislação, que regulamenta a queimada da cana, a região está sujeita.

\section{Metodologia}

De caráter quali-quantitativo, esteartigo, busca correlacionar as variáveis mecanização, legislação e queimada da cana-de-açúcar - de modo a identificar qual o papel da mecanização para a redução das queimadas.

Essa análise tem como base a legislação federal e dos estados do Mato Grosso do Sul e de Goiás (locus desta análise) com relação à proibição das práticas de queimada. A utilização de publicações científicas da área ampara às discussões conceituais, a partir de dados secundários, assim como os dados primários ofertados, principalmente pelas organizações responsáveis pela divulgação das estatísticas do setor, permitem estabelecer a análise.

Os dados obtidos sobre área plantada, área colhida com a utilização da mecanização e consequentemente, da área na qual ainda ocorre a queimada foram obtidos por meio do Censo Varietal de 2012, publicado pelo Centro de Tecnologia Canavieiro (CTC), além de dados divulgados pelo Instituto Brasileiro de Geografia e Economia (IBGE). 


\section{Resultados e discussões}

É possível perceber que no período entre 1990 e 2003 (13 anos), a expansão nacional da cana-de-açúcar foi de $51 \%$, tendo os estados de Mato Grosso e Paraná, como os mais representativos em taxas de crescimento, respectivamente $383 \%$ e $172 \%$.

Ao considerar a nova fase de expansão agrícola, de 2003 a 2013 (10 anos), que ocorre após o advento do carro bicombustível, a expansão nacional alcança $94 \%$, sendo os estados de GO e MS os que mais cresceram em área, respectivamente, $437 \%$ e $369 \%$. Diante desses dados, pode-se afirmar que grande parte da expansão da cana-de-açúcar no país, nos últimos anos, ocorreu nesses dois estados.

Considerando o mencionado período de 1990 a 2013, verifica-se que as expansões mais expressivas ocorreram no Centro-Oeste (principal nova fronteira agrícola da cana). Os estados da região sudeste (PR, MG e SP) apresentaram uma média um pouco superior ànacional, e os estados do Nordeste - em específico Alagoas e Pernambuco - apresentaram crescimento ínfimo e negativo, respectivamente.

Entretanto, o crescimento que favoreceu o aumento da produção de canade-açúcar no país também ocasionou grandes problemas ambientais, entre outros de ordem social destacados na introdução deste artigo. Todavia, apesar dos diversos problemas gerados, algumas alternativas se apresentaram em busca de sanear muitos deles. Nesta pesquisa, como já delimitado anteriormente, aborda-se a mecanização da colheita como fator que favoreceu a redução da queimada da palha da cana-de-açúcar na etapa que antecede a colheita.

Alves (2009) relata que a mecanização da colheita da cana entra em discussão no país em duas fases distintas. Uma, por volta de 1970, quando os usineiros temiam a falta de mão-de-obra para a colheita e com isso os salários pagos seriam equivalentes aos pagos na zona urbana. Graziano (1981) conta que nessa época as máquinas eram usadas apenas como uma ameaça para os trabalhadores no início das safras. 
O próprio movimento da população acabou por espantar o fantasma das máquinas substituindo a mão-de-obra e o temor dos usineiros de que faltaria mãode-obra. Parte dessa dinâmica deveu-se ao êxodo de agricultores, que realizavam agricultura de subsistência em diversas regiões do país, para as regiões de cultura de cana, principalmente, os estados de São Paulo, Minas Gerais e Paraná (ALVES,1991; SILVA, 2002).

Depois em 2003, com a nova expansão agrícola, a discussão sobre a mecanização volta para agenda, dessa vez motivada pela pauta de ambientalistas que se preocupam com os efeitos da queimada e de parte dos próprios agricultores, que buscam métodos mais eficientes para a colheita, de modo que haja menos degradação ao solo e redução do custo com a mão-de-obra (ALVES, 2009).

A partir de 2003, os estados se mobilizaram elaborando legislações estaduais que regulamentam a queimada da palha da cana e estipulam um planejamento para a extinção final da queima dos canaviais. Como alternativa à queima da cana institui-se a colheita mecanizada.

No entanto, alguns estados foram mais rápidos em regulamentar a questão das queimadas e as exigências variam de estado para estado, inclusive muitas cidades também elaboraram leis municipais que proibiam a queima na área do município. Houve muita disputa judicial para esta questão, apresentando discussões acirradas em termos jurídicos, por parte dos ambientalistas e dos produtores agrícolas e também dos legisladores que elaboraram e aprovaram as leis nos âmbitos municipais e estaduais ${ }^{4}$.

No estado do Mato Grosso do Sul, o artigo 3ํ da Lei Estadual oㅜ 3404 de 2007, regulamentou a queimada dos canaviais e estipulou que a partir de 2010 houvesse uma redução gradativa da queima da cana, na ordem de $16,75 \%$ ao ano, com um prazo limite de extinção da prática prevista para 2016.

De acordo com a Associação dos Produtores de Bioenergia do Mato Grosso do Sul (Biosul), o estado é hoje aquele que possui o maior percentual da área colhida de forma mecanizada, cerca de $94 \%$ na safra de 2012/2013. Segundo o CTC

\footnotetext{
${ }^{4}$ Essas disputas podem ser verificadas nas coletâneas do Supremo Tribunal Federal com o título Queimada em canaviais: Bibliografia, Legislação e Jurisprudência Temáticas, disponível em http://www.stf.jus.br/arquivo/cms/bibliotecaConsultaProdutoBibliotecaBibliografia/anexo/BibliografiaQu eimadasCanaviais.pdf
} 
(2012) esse percentual foi de 95\%. Pequenas discrepâncias à parte, o percentual indica um índice importante para o comprometimento com a extinção completas das queimadas.

A Lei 15.834, de 23 de novembro de 2006, do estado de Goiás, é anterior a do Mato Grosso do Sul, no entanto, apresenta metas menos ousadas que as do estado vizinho. A Lei prevê uma redução de $10 \%$ da área a ser colhida de 2008 a 2012; 25\% do ano de 2013 a 2017; de 2018 a 2022 o percentual chega a metade de toda área colhida, 50\% de redução; 75\% é a taxa estipulada de 2023 a 2027 e somente em 2028 haveria extinção total da queima de palha nas lavouras de canade-açúcar.

O que se percebe é que, apesar da legislação ainda prever um tempo relativamente longo no estado de Goiás e médio no Mato Grosso do Sul, para a extinção das queimadas, os próprios produtores já estão mecanizando suas colheitas por iniciativa própria, o que vem antecipando o fim das práticas de queima.

As taxas de $95 \%$ de colheitas mecanizadas só eram previstas pela legislação do estado do Mato Grosso do Sul para o início de 2016, no entanto, em 2012 essa taxa já havia sido atingida. No estado de Goiás, apesar da taxa ainda ser menor, houve uma antecipação maior diante das exigências da legislação. 90\% era a taxa a ser atingida apenas em 2028, entretanto, em 2012 esse já era o percentual de área utilizando a colheita mecanizada de cana crua e, portanto, sem a prática da queima.

Então, se a legislação ainda não impõe tais índices de redução, a questão passa a ser: qual a motivação para que a mecanização tenha sido implementada com altas taxas e em curto espaço de tempo? Além da pressão da sociedade em geral e de muitas disputas com o ministério público especificamente, os produtores de cana-de-açúcar contam com um grande incentivo - a redução do custo de colheita comparando-se a manual com queima à mecanizada sem queima.

De acordo com Rodrigues e Saab (2007), relacionando valor em reais a área por hectare, tem-se o valor de 904,04 reais por hectare o que equivale ao custo de 8,90 reais por tonelada produzida. Para a colheita mecanizada sem queima, o valor por hectare cai para 668,36 reais, representando 6,58 reais por tonelada. Os valores 
apresentados são semelhantes ao valores encontrados em pesquisas de Kronka e Monteiro (1999) e Ripoli et al. (1999).

Tal diferença é bastante significativa, cerca de 33\% de redução no custo da operação de colheita, fato esse que tem sido um incentivo bastante atrativo para que os produtores de cana-de-açúcar implementem, em suas propriedades, a colheita mecanizada. Além disso, o aproveitamento da palha para a produção de energia, também tem representado uma outra fonte de ganhos para as usinas, o que torna a mecanização atrativa por mais um motivo.

\section{CONCLUSÃO}

Diante de tal cenário é possível afirmar que uma série de fatores está mudando as práticas para a colheita da cana-de-açúcar. Tais fatores vão desde a pressão da sociedade, seja por questões relacionadas ao meio ambiente enquanto natureza e, portanto, uma preocupação pertinente à utilização dos recursos naturais, até questões sociais que envolvem salubridade e periculosidade no trabalho de corte.

Essas questões têm sido pauta de diversas discussões e a prática das queimadas em canaviais ultrapassam as questões jurídicas e invadem debates sobre responsabilidades e competências do legislativo estadual (câmara de deputados) ou municipal (câmara de vereadores) quanto à elaboração de leis que contrariam totalmente ou em parte a Lei Federal (no caso o Código Florestal).

Em meio a todo esse debate que perpassa diversos âmbitos sociais, políticos e econômicos, pela grandeza que o setor canavieiro tem para a balança comercial brasileira, surge a tecnologia que, para atender uma demanda dos produtores, vem auxiliar na produção de máquinas colheitadeira mais eficientes, que possam ser utilizadas em áreas com declive mais acentuado e não somente em terremos totalmente planos.

Assim, diante de colheitadeiras mais eficientes e cujo custo de produção é reduzido se comparado ao que utiliza o corte manual e, portanto, a queima précolheita, a mecanização tem sido uma grande aliada para que os canaviais deixem de produzir fuligem e passem a produzir, além da cana que vai gerar açúcar e 
etanol, também biomassa que representa uma excelente alternativa de produção de energia renovável.

\section{REFERÊNCIAS BIBLIOGRÁFICAS}

ALVES, Francisco. Políticas Públicas compensatórias para a mecanização do corte de cana crua: indo direto ao ponto. RURIS-Revista do Centro de Estudos Rurais-UNICAMP, v. 3, n. 1, 2009.

Modernização da agricultura e sindicalismo: as lutas dos trabalhadores assalariados rurais na região canavieira de Ribeirão Preto. 1991. Tese (Doutorado) - IE/Unicamp, Campinas.

ANTUNES, J.F.G; AZANIA, C.A.M.; AZANIA, A.A.P.M. disponível em http://www.grupocultivar.com.br/site/content/artigos/artigos.php?id=983

KRONKA, P. F. B.; MONTEIRO, J. H. Desempenho operacional de colhedoras na Usina Iturama. In: SEMANA DE CANA DE PIRACICABA,1999, Piracicaba. Anais... Piracicaba: Saccharum, 1999. p.4648.

GONÇALVES, D. B.; FERRAZ, J. M. G.; SZMRECSÁNYI, T. Agroindústria e meio ambiente. In: ALVES, F. et al. (Org.). Certificação socioambiental para a Agricultura: desafios para o setor sucroalcooleiro. Piracicaba (SP): Imaflora; São Carlos (SP): Edufscar, 2008.

RIPOLI, T. C. C.; CARVALHO FILHO, S. M.; MOLINA JÚNIOR, W. F.; RIPOLI, M. L. C. Desempenho econômico de colhedora em cana crua. Engenharia Rural, Piracicaba, v. 12, p. 1-5, 2001.

RODRIGUES, Euripedes Bomfim; SAAB, Otavio Jorge Grigoli Abi. Avaliação técnico-econômica da colheita manual e mecanizada da cana-de-açúcar (saccharumspp) na região de BandeirantesPr. Semina: Ciências Agrárias, v. 28, n. 4, p. 581-588, 2007.

SILVA, M. A. M. Errantes do Fim do Século. Araraquara: EDUNESP, 2002.

\section{Legislação}

BRASIL. LEI № 12.651, DE 25 DE MAIO DE 2012.

GOIAS. Lei Estadual N 15.834, DE 23 DE NOVEMBRO DE 2006

MATO GROSSO DO SUL. Lei Estadual n.3357, DE 9 DE JANEIRO DE 2007 